\title{
Lexical access and the spelling-to-sound regularity effect
}

\author{
DAVID W. BAUER \\ University of California, San Diego, La Jolla, California 92037 \\ and \\ KEITH E. STANOVICH \\ Oakland University, Rochester, Michigan 48063
}

\begin{abstract}
A number of investigators have reported that words that follow spelling-to-sound rules can be recognized faster than words that violate such rules (the "regularity" effect). On occasion, the absence of a regularity effect is reported, however. The first two experiments of the present paper report that a regularity effect can be obtained in a lexical decision task with word sets that previously have been reported not to produce such an effect, when consideration is given to the consistency or inconsistency of the pronunciations of each word's visually similar "neighbors." Subsequent experiments demonstrated that the obtained regularity effect does not vary as a function of mixed-vs. single-case presentation (Experiment 3 ) or visual quality (Experiment 4) in a lexical decision task. These results are explained in terms of Glushko's (1979) activation and synthesis model of lexical access. It is argued that the obtained results are incompatible with traditional dual process models of lexical access (which incorporate separate visual and phonological pathways and spelling-to-sound rules) and fully compatible with Glushko's model. It is concluded that spelling-to-sound regularity is not a property of a word in isolation, but rather a property of a word in the context of visually similar words that are activated in the course of recognition.
\end{abstract}

How words are accessed in the internal lexicon has implications for models of word recognition (Barron, 1978), associative models of memory (e.g., Anderson \& Bower, 1973), priming studies (e.g., Meyer, Schvaneveldt, \& Ruddy, 1975), and theories of reading (e.g., Smith, 1971). It is thus not surprising that so much experimentation has been devoted to investigating factors affecting lexical access.

In recent years, much attention has been focused on determining the relative importance of visual and phonological information in lexical access. Some suggestive (but preliminary) data come from the neurological literature. Marshall and Newcombe (1973) and Shallice and Warrington (1975) reported that patients termed phonemic dyslexics demonstrated an impaired ability to utilize a phonological code in accessing the lexicon. Patterson and Marcel (1977) reported that certain patients with left-hemisphere brain damage were unable to read nonwords but could repeat such items when they were presented auditorily. This finding suggests

This research was supported in part by NSF Grant BNS7824772. The authors wish to thank Jeff Miller, Bob Glushko, and Jon Baron for their helpful comments on an earlier draft of this manuscript, and Kurtis Smith and Michael Seiler for assistance in data collection. Requests for reprints should be sent to Keith E. Stanovich, Department of Psychology, Oakland University, Rochester, Michigan 48063. that a spelling-to-sound conversion process had been disrupted in these patients.

In addition, Patterson and Marcel (1977) report that, in a lexical decision task, phonemic dyslexics respond as fast to nonword homophones as to nonhomophones. This finding contrasts with data from normals, who show a marked slowing of responses for pseudohomophones (Rubenstein, Lewis, \& Rubenstein, 1971). Since both groups (normals and brain-damaged patients) were able to recognize nonwords as such, the implication is that for the latter group of patients, only the visual access route is operational (see also Saffran \& Marin, 1977). Thus, from such evidence, it would seem that a purely visual route to the lexicon exists. Brain-damaged patients seem to have lost the ability to utilize a phonological code to access the lexicon.

Although the studies of brain-damaged patients appear to give an unequivocal answer to the question of whether lexical access can occur on a purely visual basis, the more complicated question of whether lexical access in normal readers is based primarily on visual or phonological information has generated much empirical and theoretical work, and it continues to do so (e.g., Baron, 1977; Barron \& Baron, 1977; Coltheart, Davelaar, Jonasson, \& Besner, 1977; Kleiman, 1975; Levy, 1978; Martin, 1978; Meyer, Schvanefeldt, \& Ruddy, 1974; Shulman, Hornak, \& Sanders, 1978; Theios \& Muise, 
1977). Although many different experimental paradigms that produce data relevant to this problem have been introduced into the literature, Baron and Strawson (1976) have employed one of the simplest. Their experiments centered around the existence of a spelling-tosound regularity effect in word recognition. That is, they found that subjects named lists of words that followed spelling-to-sound correspondence rules (as defined by Venezky, 1970, for example) faster than lists of words not following such rules (e.g., "have"). Subsequent work by Stanovich and Bauer (1978) using a discrete-trial procedure replicated the findings of a statistically reliable regularity effect (although the magnitude of the effect was considerably smaller than that observed by Baron and Strawson). In addition, Stanovich and Bauer found that the findings could be replicated in the lexical decision paradigm. They obtained a regularity effect comparable in size to that obtained in the naming task. A regularity effect of a magnitude similar to that obtained by Stanovich and Bauer has been obtained by other researchers employing both the lexical decision task (e.g., Barron, 1979) and the naming task (e.g., Glushko, 1979; Gough \& Cosky, 1977).

Thus, the regularity effect has been observed in five different laboratories. However, in two separate experiments Coltheart, Besner, Jonasson, and Davelaar (1979) failed to find a regularity effect in a lexical decision task (the null findings of Mason, 1978, are discussed below). This contradiction in the literature is somewhat puzzling and requires a resolution. Possibly, the explanation lies in the different word sets used by different experimenters. Our first experiment was thus an attempt to replicate the Coltheart et al. (1979) experiment using their set of words. This was done to rule out explanations based on methodological and/or equipment considerations.

\section{EXPERIMENT 1}

\section{Method}

Subjects. The subjects were 20 undergraduate psychology students recruited through a subject pool at Oakland University.

Stimuli and Apparatus. The subjects saw 132 stimuli in the experiment. Six of the items (three words and three nonwords) served as practice stimuli. Of the remaining 126 stimuli, 78 were words and 48 were nonwords. The 78 words were those used by Coltheart et al. (1979). The 39 regular words and the 39 irregular words were closely matched for word frequency, number of letters, number of syllables, number of morphemes, concreteness/imageability, and part of speech. These 78 words appear in Appendix A. The 48 nonwords were all pronounceable.

The stimuli were typed on $6 \times 9$ in. $(15.2 \times 22.9 \mathrm{~cm})$ cards in uppercase Prestige Elite font with an IBM Selectric II typewriter. The stimuli were presented via an Iconix tachistoscope at a viewing distance of $88.9 \mathrm{~cm}$. Five-letter words subtended a horizontal visual angle of approximately $.65 \mathrm{deg}$. A continuously illuminated black fixation point was located in a separate field and was positioned $.2 \mathrm{deg}$ below the center of the stimulus. Stimulus onset was controlled by a button pushed by the subject. This button caused the stimulus to be displayed and simultaneously started a millisecond clock. When the subject responded verbally to the target, a voice-activated relay stopped the clock.

Procedure. Subjects were instructed to fixate the black fixation point and were informed that they would be shown strings of letters, some of which would form words and some of which would not. Subjects were told to push the button upon a "ready" signal given by the experimenter and to indicate as quickly as possible whether or not the letter string was a word. They were told to vocally respond "yes" if the string was a word and "no" if the string was not a word. The subjects were not informed that the first six trials were practice. The 126 experimental stimuli were presented in a random order, with the constraint that no one stimulus type (regular word, irregular word, or nonword) appear more than three times in a row.

\section{Results and Discussion}

Trials on which some type of experimental malfunction occurred were dropped from the data analysis. Trials on which the subject made the wrong decision or had a response longer than 3 standard deviations above the mean for that condition were also dropped from the analysis. Across subjects, the mean reaction time to the regular words was $839 \mathrm{msec}$ and the reaction time to the irregular words was $829 \mathrm{msec}$. This difference is in the opposite direction of the usual regularity effect and was nonsignificant $[t(19)=1.41]$. The mean reaction time for the nonwords was $1,003 \mathrm{msec}$. Error percentages were $3.2 \%$ and $2.8 \%$ for the regular and irregular words, respectively.

The results of Experiment 1 have thus replicated the absence of a regularity effect observed by Coltheart et al. (1979) using the word list employed by those investigators. This finding suggests the discouraging conclusion that the regularity effect arises only with certain word sets. However, one possible explanation for the failure to find a regularity effect with the Coltheart et al. (1979) words has been suggested by Baron (Note 1). He reports that a number of the Coltheart et al. exception words were not true exceptions and that after removing these items from the Coltheart et al. data, the regularity effect was significant in one experiment and nearly so in the other. Another explanation for the null finding is suggested in a recent paper by Glushko (1979), in which he describes a model of lexical access that includes an explanation for the regularity effect. The model was originally designed to handle naming (pronunciation) data, but it can easily be extended to include the lexical decision task. In Glushko's (1979) activation and synthesis model, entry to the lexicon takes place initially on a visual basis. Lexical entries that share spelling units with the presented word (or nonword) are activated. (See Taft, 1979, for a more complete discussion of spelling patterns.) The degree to which any particular lexical entry becomes activated is dependent on the degree to which that item and the stimulus share spelling patterns. In general, ends of words tend to be the most important units (e.g., rhymes are considered with respect to the ends of words), although it is likely that there is some effect of the other parts of the word as well. The greater the number 
of shared units, the greater is the activation. Each of these activated words automatically activates its respective pronunciation. According to this model, only at this point do pronunciations play any role in lexical access. Once activated, the pronunciations associated with each word tend to activate other words with similar pronunciations. The result of this process is a network of activated words. ${ }^{1}$

Consider the word "take." When this word is presented, other words like "make," "rake," and "bake" will become activated along with "take," due to the shared "ake." Each of these words activates its pronunciation, which serves to activate other words with similar pronunciations. However, the words that become activated due to pronunciation similarities are the same words that were activated by their visual similarity to the presented item. What is apparent is that the same set of words tends to be activated and reactivated. The set of activated words appears to be closed. "Take" is a regular word with a consistent neighborhood. A consistent neighborhood is one in which the lexical items that become activated due to visual similarity to the target item are the same as those lexical entries that become activated due to similarity in pronunciation.

Now consider a word like "treat." Words like "meat," "beat," and "seat" will become activated due to shared spelling units. In addition, the word "great" is also activated. Again, the associated pronunciations of each word become active and serve to activate other words with similar pronunciations. However, the word "great" activates words like "grate," "hate," and "rate," which have similar pronunciations. The result of this is that a large number of words become activated, many of which have nothing in common with the target word. The set of words activated by an inconsistent word like "treat" is open, not closed. An inconsistent neighborhood is one in which the lexical entries activated by visual similarity differ from those lexical items activated by similarity of pronunciation. In order to produce a regularity effect, then, all that is needed is a decision mechanism that finds the most strongly activated word. When there are many possible words to test, this process is slower than when there are few. Note also that, with this model, there is a mechanism for observing a "regularity" effect for nonwords that share spelling units with actual words, which is analagous to that for words. In fact, Glushko (1979) has reported obtaining a nonword regularity effect (e.g., "mave" is responded to slower than "mape").

In the context of Glushko's (1979) model, the terms "exception" and "regular" assume very different meanings. For example, a word like "save" is regular in that it follows spelling-to-sound rules, but it is inconsistent in that one of the members of its neighborhood is "have." As Glushko notes, "classifying words as 'regular' or 'exception' is more than a preliminary to stimulus selection. Instead, it presupposes a theory of reading" (1979, p. 684). In an important experiment, Glushko (1979) demonstrated that words that had been classified as regular can be just as inconsistent as so-called exception words. He found that such regular inconsistent words were named significantly slower than regular consistent words. This finding suggests a possible explanation for the absence of a regularity effect in the data of the present Experiment 1 and in the experiments of Coltheart et al. (1979). If the regular words in the set of words used in these experiments consist of many inconsistent items, a regularity effect would not be expected. An examination of the word set revealed that, using Glushko's (1979) criteria, 12 of the 39 regular words were inconsistent. Thus, it may be that the reaction times associated with the regular inconsistent words reduced the average difference between reaction times for regular and irregular words in the results of Coltheart et al. and our Experiment 1.

\section{EXPERIMENT 2}

In Experiment 2, the Coltheart et al. (1979) set of words is examined more carefully, in an attempt to reconcile the absence of a regularity effect for this stimulus list with reports of a reliable regularity effect by other investigators. Thus a subset of the Coltheart et al. stimuli was employed in order to investigate whether there are reaction time differences between the regular inconsistent, regular consistent, and exception words in that particular list.

\section{Method}

Subjects. The subjects were 16 graduate and undergraduate psychology students at the University of California at San Diego. The graduate students took part in the experiment on a volunteer basis. The undergraduates served in the experiment as partial fulfillment of an introductory course requirement. All subjects were right-handed.

Stimuli. There were five types of stimulus items presented. Nine of the single-syllable regular inconsistent words from the Coltheart et al. (1979) list were used. Only single-syllable words were used, since a description of the neighborhood of multisyllable words is dependent on the relative importance of the different syllables in the word. Thus, it is difficult to determine consistency or inconsistency. These nine inconsistent words were matched with an equal number of regular consistent and exception words, also taken from the Coltheart et al. list. These words were picked such that each word in each type was matched for frequency. Nine additional words were picked that did not appear on the Coltheart et al. list, to bring the total number of words to 36. These words appear in Appendix B. Thirty-six pronounceable nonwords were also generated. All stimuli appeared in uppercase.

Apparatus. A Terak 8510 microprocessor controlled the presentation of stimuli and the recording of responses and response latencies. A keyboard attached to the computer measured reaction times. The stimuli were presented on a Terak display device attached to the computer and appeared as white characters on a black background. A five-letter word subtended approximately $4.5 \mathrm{deg}$.

Procedure. Subjects were seated in front of the screen, and instructions for the task were then given. The nature of the lexical decision task was described, and subjects were instructed to respond as quickly and accurately as possible. Each trial was preceded by a fixation point that remained in view for $500 \mathrm{msec}$ and was followed $250 \mathrm{msec}$ later by the stimulus. The stimulus 
remained in view until the subject responded. Accuracy feedback was given for $750 \mathrm{msec}$, followed $1,000 \mathrm{msec}$ later by the fixation for the next trial. "Word" responses were made with the right index finger, and "nonword" responses were made with the left index finger. Each subject served in one block of 72 trials, receiving accuracy feedback after each trial.

\section{Results and Discussion}

Across subjects, the mean reaction time for regular inconsistent words was $660 \mathrm{msec}$, for regular consistent it was $603 \mathrm{msec}$ and for exception words it was $631 \mathrm{msec}$. The mean percentages of correct responses were $93 \%$, $97 \%$, and $90 \%$, for the inconsistent, consistent, and exception words, respectively. An analysis of variance was performed on these data, using the three levels of the word-type factor that were of interest (regular consistent, regular inconsistent, and exception). The main effect of word type was significant for both the reaction time data $[F(2,30)=4.44, p<.05]$ and the error data $[F(2,30)=4.37, p<.05]$. The difference between the reaction times for the inconsistent and consistent regular words was significant $[\mathrm{t}(15)=4.07$, $p<.001]$. The difference between the inconsistent and exception words was not significant $[\mathrm{t}(15)=1.05$, $p>.1]$, nor was the difference between consistent and exception words, although the latter approached significance $[t(15)=-1.59, p<.1]$. However, the accuracy differences between the consistent and exception words was significant $[t(15)=3.59, p<.005]$. No other reliable differences were found.

The results of Experiment 2 confirm the possibility that the failure to find a regularity effect with the Coltheart et al. (1979) words may be due to the presence of a number of inconsistent regular words. A regularity effect was obtained (in the error rates) with a subset of their word set, once inconsistent words were removed. A regularity effect can probably be obtained when a uniform definition of regularity is adopted.

\section{EXPERIMENT 3}

Several investigators have adopted a dual-access model to explain the results of experiments on lexical access (e.g., Baron, 1973; Baron \& Strawson, 1976; LaBerge, 1972; Meyer et al., 1974; Shulman \& Davison, 1977; Spoehr, 1978). In such a model, it is hypothesized that two separate pathways lead to the lexicon; one is accessed via a visual code, and the other is accessed via a phonological code, with the visual pathway usually being the faster of the two.

Glushko's (1979) activation and synthesis model represents a major alternative to the dual access conception. Here, the role of phonological information is quite different. Phonological information combines with visual information only after the visual route has made contact with the lexicon. One way to distinguish the dual access model from the activation and synthesis model lies in the predictions that each makes concerning the effect of disrupting the visual access route on the regularity effect. The activation and synthesis model predicts that the size of the regularity effect should be unchanged, since the regularity effect arises after contact with the lexicon. Initial contact with the lexicon may be slowed by disrupting the visual quality of the stimulus, but once such access occurs, activation should proceed in the usual manner. In other words, once a word becomes activated, how it became activated is irrelevant. However, if there are really two separate pathways (one visual, the other phonological), as hypothesized by the dual access model, then under such conditions the regularity effect should increase (see Baron \& Strawson, 1976). Mason (1978) addressed this issue when she looked for a regularity effect in a naming task in which the unitary structures of the words were disrupted by case mixing. Case manipulation was expected to disrupt the visual processing of words (which presumably involves supraletter information) but leave the phonological route relatively intact. However, Mason failed to obtain a regularity effect in either the single-case (lower case) or mixed-case conditions.

There are several possible reasons for Mason's (1978) failure to obtain the regularity effect. First, she reports that items were repeated across blocks. Thus the subject saw each item twice (once in lowercase and once in mixed case). Scarborough, Cortese, and Scarborough (1977) have demonstrated that repetitions produce marked effects in processing. In addition, exception and regular words were blocked in the Mason (1978) experiment. This might well have induced different strategies in the different conditions. For example, Davelaar, Coltheart, Besner, and Jonasson (1978) have demonstrated that subjects will vary their strategy in a lexical decision task, depending on the type of nonwords used. There is also some indication of a speed-accuracy tradeoff problem in the Mason data (see Mason, 1978, Tables 1 and 2). In all but one of the conditions of Mason's Experiments 1 and 2, more errors were made on exception word trials than on regular word trials. Thus a regularity effect is indicated in the error rates. A final problem with Mason's experiment is that she used Baron and Strawson's (1976) Experiment 2 stimuli, which were (deliberately) unbalanced in word frequency. The exception words had higher word frequencies, an imbalance that would work against the regularity effect. It should also be noted that, although not statistically significant, the mean reaction times for the exception and regular words in the mixed-case condition were in the direction indicating a regularity effect and were of a magnitude similar to others reported in the published literature. In light of the above-mentioned difficulties of the Mason (1978) experiments, further study of the case-type variable and the regularity effect seemed in order, and thus Experiment 3 was conducted.

\section{Method}

Subjects. The subjects were 24 University of California, San Diego, undergraduates who took part in the experiment 
in partial fulfillment of an introductory course requirement. All were right-handed, with normal or corrected-to-normal vision.

Stimuli and Apparatus. The stimuli consisted of two sets of 100 words and 50 nonwords. Each set contained 50 regular (consistent) words and 50 exception words. Set A consisted of the words used in the Stanovich and Bauer (1978) experiments. The regular and exception words were matched on word length and word frequency (mean regular frequency $=64.5$ and mean exception frequency $=64.6$, according to the Kucera \& Francis, 1967, count). Whenever possible, a regular word was chosen so that there was a close graphemic correspondence between it and an exception word, thus insuring that the two types did not differ in the sequential constraints of their component letters. Set B was constructed in the same way as Set A. The mean frequency of the words in Set B was 63.7 for both types of words (Kučera \& Francis, 1967). Lowercase and mixed-case versions of each word set were created. In the mixedcase condition, the case (uppercase or lowercase) of the first letter of each stimulus was randomly selected. Subsequent letters in that stimulus alternated in case. These word sets appear in Appendixes C and D. An Automated Data Systems Micro-8 computer controlled the presentation of stimuli and the recording of responses and response latencies. The stimuli were presented on a Digital Equipment Corporation display device. Responses were made on a microswitch keyboard.

Design. Each subject was run in two blocks of 150 trials. Each subject was presented lowercase stimuli in one block and mixed-case stimuli in the other. Lowercase was chosen as the single-case condition to extend the regularity effect to that case. One block was run using word Set A, and the other was run using word Set B. Order of word set and case presentation were counterbalanced across subjects.

Procedure. Subjects were seated in front of the display and told that they would be seeing a string of letters appear on the screen. They were told that their task was to decide whether that string of letters was or was not a word. They were also informed as to the case of the stimuli for that block. Both speed and accuracy were emphasized. Twelve practice items were given before each block. At the conclusion of the first block, subjects were given a short rest, followed by information about the case of the stimuli for the second block. In all other ways, the procedure was identical to that of Experiment 2.

\section{Results and Discussion}

Mean reaction time and percentage error were calculated for each subject for regular and irregular words for both the lowercase and mixed cases. These data appear in Table 1. Reaction times and error rates were subjected to an analysis of variance with a betweensubjects factor of group (formed by the pairing of case order and word set) and within-subjects factors of case and word class (regular or exception). For the reaction time data, the $157-\mathrm{msec}$ difference between lowercase and mixed case was significant $[F(1,20)=57.65$, $\mathrm{p}<.001]$, as was the 26 -msec advantage of regular words over exception words $[F(1,20)=18.69, p<.001]$.

Table 1

Mean Reaction Times (in Milliseconds) for Experiment 3

\begin{tabular}{lccccc}
\hline & \multicolumn{2}{c}{ Lowercase } & & \multicolumn{2}{c}{ Mixed Case } \\
\cline { 2 - 3 } \cline { 5 - 6 } & Mean & ER & & Mean & ER \\
\hline Regular & 628 & 2.7 & 778 & 6.1 \\
Exception & 646 & 3.1 & 811 & 6.5 \\
\hline
\end{tabular}

Note-ER = error rate.
The group main effect did not reach significance. The Case by Word Type interaction did not approach significance $[F(1,20)=1.48]$. No other interactions were significant. The error data revealed only a main effect of case, with mixed-case presentation producing $3.94 \%$ more errors than lowercase presentation $[F(1,20)=$ $55.52, \mathrm{p}<.001]$.

Thus, a regularity effect was obtained with both a lowercase presentation and a mixed-case presentation. Furthermore, the size of the regularity effect did not change significantly as a result of such a manipulation. Such a finding is consistent with Glushko's (1979) model of lexical access and appears to be inconsistent with a dual access model. If the regularity effect were due to the differential ability of regular and exception words to take advantage of two separate pathways to the lexicon, and if (as seems reasonable) the case manipulation served to disrupt the unitary nature of a word (McClelland, 1976), then the visual pathway should be interfered with to a greater degree than the phonological route. This would place a greater reliance on the phonological route, thus increasing the usual regularity effect. The fact that such a finding was not observed casts doubt on such a theory.

Another way in which the visual pathway of a twoprocess model might be interfered with is through the use of visual degradation. Stanovich and Bauer (1978, Experiment 4) attempted to test such a theory by degrading the stimuli in a naming task. Again, if two separate codes are used to access the lexicon, then the regularity effect should have increased when the visual quality was reduced. In fact, it was found that the regularity effect actually decreased in size with reduced contrast, although this trend was nonsignificant. Due to this unexpected suggestion of a disappearance of the regularity effect, as well as the important theoretical issues involved, it was thought that a closer examination of the effects of visual degradation was needed. Stanovich and Bauer (1978, Experiment 4) achieved degradation through the use of contrast reduction. The goal was to break up the unitary nature of words through this technique, but it could be argued that such a manipulation might increase reliance on supraletter information due to the reduced quality of the individual letters. It was felt that a visual quality manipulation that introduced visual noise to the stimuli would be a more appropriate method for disrupting the unity of words.

\section{EXPERIMENT 4}

\section{Method}

Subjects. The subjects were 16 undergraduate psychology students recruited through an introductory psychology course pool and the University of California at San Diego.

Stimuli and Apparatus. The stimuli and apparatus were identical to those used in Experiment 3. Each letter was contained in a 7 by 9 dot matrix. In the degraded condition, some of the dots that made up each letter were displaced, creating a blurred and misshapen character. Each word set appeared in both visual quality conditions equally of ten across subjects. 
Procedure. Subjects were seated in front of the screen and given instructions. They were told to decide whether or not each letter string was a word and to respond as quickly and accurately as possible. Each trial was preceded by a fixation that remained in view for $500 \mathrm{msec}$. There was a $300-\mathrm{msec}$ blank interval, followed by the stimulus string, which remained in view until the subject responded. This was followed by accuracy feedback for $750 \mathrm{msec}$. The next trial began $1,000 \mathrm{msec}$ later. Within each block, the words were presented in a random order. All subjects completed one block of trials under normal contrast conditions and one block under reduced contrast. The order of word set (A or B) and visual quality conditions were counterbalanced across subjects.

\section{Results and Discussion}

For each subject, mean reaction times and percentage errors were collected for each word class under both visual conditions. These means, collapsed across subjects, appear in Table 2. Mean reaction times for each item appear in Appendixes C and D. An analysis of variance on the reaction time data treating subjects as a random variable revealed significant main effects of visual quality $[F(1,12)=6.75, p<.05]$ and regularity $[F(1,12)=9.4$, $p<.01]$. The interaction of visual quality and the regularity effect did not approach significance $[F(1,12)=$ $.05, \mathrm{p}>.1]$. No other main effects or interactions were significant. The error data revealed main effects of visual quality $[F(1,12)=14.95, p<.01]$ and regularity $[F(1,12)=9.4, p<.01]$. An analysis of variance treating items as the random factor revealed identical findings, with the main effects of visual quality $[F(1,196)=25.98$, $\mathrm{p}<.001]$ and regularity $[\mathrm{F}(1,196)=8.06, \mathrm{p}<.01]$ attaining significance and the Visual Quality by Regularity interaction not approaching significance $[\mathrm{F}(1,196)=.55$, $\mathrm{p}>.1] .^{2}$ For the error data, only a main effect of visual quality reached significance $[F(1,196)=11.06, p<.001]$.

Thus, we find that there is no observable increase in the regularity effect when the visual quality (and so visual unity) of the stimulus is disrupted. This finding, coupled with a similar finding with the case manipulation (Experiment 3), offers strong support for a model similar to that of Glushko (1979) and appears to be incompatible with the dual access model as it is usually specified.

\section{GENERAL DISCUSSION}

The present experiments have attempted to explain apparent discrepancies in findings related to the spellingto-sound regularity effect. The most basic inconsistency in the literature stemmed from the Coltheart

Table 2

Mean Reaction Times (in Milliseconds) for Experiment 4

\begin{tabular}{lccccc} 
& \multicolumn{2}{c}{ Normal } & & \multicolumn{2}{c}{ Degraded } \\
\cline { 2 - 3 } & Mean & ER & & Mean & ER \\
\hline Regular & 661 & 3.1 & 712 & 5.4 \\
Exception & 699 & 5.4 & 753 & 7.6 \\
\hline
\end{tabular}

Note-ER = error rate. et al. (1979) experiments, reporting an absence of the regularity effect. Experiments 1 and 2 attempted to reconcile this finding with the more typical reports of the existence of such an effect. In order to accomplish this, it became necessary to consider a somewhat different definition of regularity. It is only within the framework of Glushko's (1979) activation and synthesis model that the Coltheart et al. findings are comparible with previous results. When a word's neighborhood is considered, rather than its correspondence or noncorrespondence with spelling-to-sound rules, a dichotomy between consistent and inconsistent words arises. A consistent neighborhood is one in which the items that a target activates on the basis of visual similarity are identical to those subsequently activated by pronunciation similarity. An inconsistent neighborhood is one in which the items that become activated due to visual similarities are not perfectly redundant with the items that become activated due to shared pronunciations. What gives rise to the regularity effect, then, is not spelling-to-sound rules, but rather the consistency or inconsistency of the set of words activated by the target word.

In support of such an activation model, our Experiments 3 and 4 demonstrated that the regularity effect fails to increase when the unitary nature or visual quality of the stimuli are disrupted. Models of lexical access that include two pathways (one phonological and one visual) would predict that such manipulations should increase the dependence of lexical access on the phonological route. This would result in a further advantage for regular words over exception words. Glushko's (1979) model, on the other hand, predicts no change in the regularity effect, since the effect of phonology arises after the visual code has made initial contact with the lexicon. In that sense, the regularity effect does seem to be postlexical, as Stanovich and Bauer (1978) suggested.

It should also be noted that the activation and synthesis model is consistent with the results of Experiment 3 of the Stanovich and Bauer (1978) paper, in which it was found that forcing subjects to speed their responses eliminated the regularity effect. Under such conditions, the subject must terminate processing before lexical activation has been completed. In general, only the words most closely associated with the target would become activated. On the average, this would result in less inconsistent information becoming activated for the exception words, resulting in the diminishing or disappearance of the usual regularity effect.

It seems likely, then, that the spelling-to-sound regularity effect does not arise as a result of the application of spelling-to-sound rules to produce a phonological code, as has been hypothesized by proponents of dual access models. Instead, all of the available data seem to suggest that the effect is due to the nature of the activated neighborhoods of consistent and inconsistent words. Indeed, with such a conception, the distinction between regular and irregular words becomes consider- 
ably blurred. While it is certainly true that all irregular words activate inconsistent information during lexical access, it is also the case that some "regular" words activate as much inconsistent information. Thus, it is neighborhoods, not spelling-to-sound rules, that determine regularity and consistency.

\section{REFERENCE NOTE}

1. Baron, J. Personal communication, September 26, 1979.

\section{REFERENCES}

Anderson, J. R., \& Bower, G. H. Human associative memory. Washington, D.C: Winston, 1973.

Baron, J. Phonemic stage not necessary for reading. Quarterly Journal of Experimental Psychology, 1973, 25, 241-246.

BARON, J. Mechanisms for pronouncing printed words: Use and acquisition. In D. LaBerge \& S. Samuels (Eds.), Basic processes in reading: Perception and comprehension. Hillsdale, N.J: Erlbaum, 1977.

BARON, J. Orthographic and word-specific mechanisms in children's reading of words. Child Development, 1979, 50, 60-72.

Baron, J., \& Strawson, C. Use of orthographic and wordspecific knowledge in reading words aloud. Journal of Experimental Psychology: Human Perception and Performance, 1976, 2, 386-393.

Barron, R. W. Access to the meanings of printed words: Some implications for reading and learning to read. In F. B. Murray (Ed.), The recognition of words: IRA series on the development of the reading process. Newark, Del: International Reading Association, 1978.

Barron, R. W. Visual-orthographic and phonological strategies in reading and spelling. In U. Frith (Ed.), Cognitive processes in reading. London: Academic Press, 1979.

Barron, R. W., \& Baron, J. How children get meanings from printed words. Child Development, 1977, 48, 587-594.

Brooks, L. Nonanalytic concept formation and memory for instances. In E. Rosch \& B. Lloyd (Eds.), Cognition and categorization. Potomac, Md: Erlbaum, 1978. (a)

Brooks, L. Non-analytic correspondences and pattern in word pronunciation. In J. Requin (Ed.), Attention and performance VII. Hillsdale, N.J: Erlbaum, 1978. (b)

Coltheart, M., Besner, D., Jonasson, J. T., \& Davelaar, E. Phonological encoding in the lexical decision task. Quarterly Journal of Experimental Psychology, 1979, 31, 489-508.

Coltheart, M., Davelaar, E., Jonasson, J. T., \& Besner, D. Access to the internal lexicon. In S. Dornic (Ed.), Attention and performance VI. Hillsdale, N.J: Erlbaum, 1977.

Davelaar, E., Coltheart, M., Besner, D., \& Jonasson, J. T. Phonological recoding in lexical access. Memory \& Cognition, $1978,6,391-402$.

Glushko, R. The organization and activation of orthographic knowledge in reading aloud. Journal of Experimental Psychology: Human Perception and Performance, 1979, 5, 674-691.

Gough, P. B., \& Cosky, M. J. One second of reading again. In N. J. Castellan, D. B. Pisoni, \& G. R. Potts (Eds.), Cognitive theory (Vol. 2). Hillsdale, N.J: Erlbaum, 1977.

KLE Iman, G. M. Speech recoding in reading. Journal of Verbal Learning and Verbal Behavior, 1975, 14, 323-339.

Kućera, H., \& Francis, W. N. Computational analysis of present-day American English. Providence, R.I: Brown University Press, 1967.

LABERGE, D. Beyond auditory coding. In J. F. Kavanagh \& I. G. Mattingly (Eds.), Language by ear and eye. Cambridge, Mass: M.I.T. Press, 1972.
LEVY, B. A. Speech processing during reading. In A. M. Lesgold, J. W. Pellegrino, S. D. Fokkema, \& R. Glaser (Eds.), Cognitive psychology and instruction. New York: Plenum, 1978.

Marshall, J. C., \& Newcombe, F. Patterns of paralexia: A psycholinguistic approach. Journal of Psycholinguistic Research, 1973, 2, 175-199.

Martin, M. Speech recoding in silent reading. Memory \& Cognition, 1978, 6, 108-114.

Mason, M. From print to sound in mature readers as a function of reader ability and two forms of orthographic regularity. Memory \& Cognition, 1978, 6, 568-581.

McClelland, J. L. Preliminary letter identification in the perception of words and nonwords. Journal of Experimental Psychology: Human Perception and Performance, 1976, 2, 80-91.

Meyer, D., Schvaneveldt, R., \& Ruddy, M. Functions of graphemic and phonemic codes in visual word recognition. Memory \& Cognition, 1974, 2, 309-321.

Meyer, D., Schyaneveldt, R. W., \& Ruddy, M. G. Contextual effects on word recognition. In P. M. A. Rabbitt \& S. Dornic (Eds.), Attention and performance $V$. New York: Academic Press, 1975.

Patterson, K., \& Marcel, A. Aphasia, dyslexia, and the phonological code of written words. Quarterly Journal of Experimental Psychology, 1977, 29, 307-318.

Rubenstein, H., Lewis, S. S., \& Rubenstein, M. Evidence for phonemic recoding in visual word recognition. Journal of Verbal Learning and Verbal Behavior, 1971, 10, 645-657.

Saffran, E. M., \& Marin, O. S. M. Reading without phonology: Evidence from aphasia. Quarterly Journal of Experimental Psychology, 1977, 29, 515-525.

Scarborough, D. L., Cortese, C., \& Scarborough, H. S. Frequency and repetition effects in lexical memory. Journal of Experimental Psychology: Human Perception and Performance, 1977, 3, 1-17.

Shallice, T., \& W arrington, E. Word recognition in a phonemic dyslexic patient. Quarterly Journal of Experimental Psychology, $1975,27,148-160$.

Shulman, H. G., \& Davison, T. C. B. Control properties of semantic coding in a lexical decision task. Journal of Verbal Learning and Verbal Behavior, 1977, 16, 91-98.

Shulman, H. G., Hornak, R., \& Sanders, E. The effects of graphemic, phonetic, and semantic relationships on access to lexical structures. Memory \& Cognition, 1978, 6, 115-123.

Smiтн, F. Understanding reading. New York: Holt, Rinehart, \& Winston, 1971.

Spoenr, K. Phonological encoding in visual word recognition. Journal of Verbal Learning and Verbal Behavior, 1978, 17, 127-141.

Stanovich, K. E., \& Bauer, D. W. Experiments on the spellingto-sound regularity effect in word recognition. Memory \& Cognition, 1978, 6, 410-415.

TAFT, M. Lexical access via an orthographic code: The basic orthographic syllabic structure (BOSS). Journal of Verbal Learning and Verbal Behavior, 1979, 18, 21-39.

Theios, J., \& Muise, J. The word identification process in reading. In N. Castellan, D. Pisoni, \& G. Potts (Eds.), Cognitive theory (Vol. 2). Hillsdale, N.J: Erlbaum, 1977.

VEnEzky, R. The structure of English orthography. The Hague: Mouton, 1970.

\section{NOTES}

1. Models somewhat similar to Glushko's (1979) activation and synthesis model have been suggested by Baron (1979) and Brooks (1978a, 1978b). Both Baron and Brooks discuss the use of analogies rather than rules in pronunciation. These authors were primarily concerned with the use of single analogies (as contrasted with Glushko's model), although the use of several 
analogies was considered. Perhaps the major distinction between the models of Baron or Brooks and Glushko is that Glushko considers the activation of words to be automatic, whereas Brooks and Baron seem to refer to the conscious use of analogies. See Glushko (1979) for a more complete description of the similarities and differences between these classes of models.

2. Item analyses were not possible in earlier experients due to equipment limitations.

Appendix A

Word Set from Experiment 1

\begin{tabular}{ll}
\hline Regular & Exception \\
\hline BARGE & ANSWER \\
BASE & AUNT \\
CAPSULE & BISCUIT \\
CHECK & BLOOD \\
COUNTY & BOROUGH \\
CULT & BOWL \\
DANDY & BREAK \\
DISTRESS & BROAD \\
DUEL & BUILD \\
FREE & BURY \\
FRESH & CASTLE \\
GANG & CIRCUIT \\
GRILL & COME \\
HORSE & COUGH \\
KEPT & DEBT \\
MILE & FLOOD \\
PINE & GAUGE \\
PLUG & GLOVE \\
PROTEIN & GONE \\
QUICK & GROSS \\
RUN & LAUGH \\
SAVE & LOSE \\
SHAMPOO & LOVE
\end{tabular}

Appendix A Continued

\begin{tabular}{ll}
\hline Regular & Exception \\
\hline SHERRY & MORTGAGE \\
SHRUG & MOVE \\
SLATE & PINT \\
SORT & PROVE \\
SPADE & SCARCE \\
SPEAR & SEW \\
SPEND & SHOVE \\
SPLENDID & SIGN \\
STREWN & SOUL \\
STUPID & STEAK \\
TAKE & SUBTLE \\
THRONG & SURE \\
TOOTH & SWORD \\
TREAT & THOROUGH \\
TROUT & THROUGH \\
TURN & YACHT \\
\hline
\end{tabular}

Appendix B

Word Set from Experiment 2

\begin{tabular}{llll}
\hline $\begin{array}{c}\text { Regular } \\
\text { Inconsistent }\end{array}$ & $\begin{array}{c}\text { Regular } \\
\text { Consistent }\end{array}$ & $\begin{array}{c}\text { Excep- } \\
\text { tion }\end{array}$ & $\begin{array}{c}\text { Matched } \\
\text { Filler }\end{array}$ \\
\hline BASE & CHECK & AUNT & DUET \\
DUEL & FRESH & BOWL & FLING \\
HORSE & GANG & BROAD & HARM \\
SAVE & MILE & BUILD & HORN \\
SPEAR & PLUG & GLOVE & SAKE \\
STREWN & SHRUG & PROVE & SALE \\
THRONG & SPADE & SHOVE & SEAL \\
TOOTH & SPEND & SOUL & SEES \\
TREAT & TROUT & YACHT & SHEET \\
\hline
\end{tabular}

Appendix C

Word Set $A$ from Experiments 3 and 4 with Reaction Times from Experiment 4

\begin{tabular}{|c|c|c|c|c|c|c|c|c|c|c|c|}
\hline \multicolumn{6}{|c|}{ Regular } & \multicolumn{6}{|c|}{ Exception } \\
\hline Item & $\mathrm{N}$ & D & Item & $\mathrm{N}$ & D & Item & $\mathbf{N}$ & D & Item & $\mathbf{N}$ & D \\
\hline ADVICE & 722 & 611 & HAND & 642 & 655 & AISLE & 1034 & 674 & IRON & 552 & 542 \\
\hline AIDE & 891 & 791 & HOLDER & 756 & 581 & ALIGN & 953 & 897 & KNOB & 640 & 736 \\
\hline ALARM & 575 & 547 & HOLY & 584 & 567 & AMONG & 586 & 573 & LIQUOR & 724 & 634 \\
\hline ALIKE & 567 & 749 & HONEY & 549 & 542 & BEAR & 688 & 743 & LOSE & 578 & 530 \\
\hline ALONE & 593 & 550 & HOST & 640 & 547 & BLOOD & 614 & 527 & MARINE & 807 & 755 \\
\hline ALONG & 573 & 696 & HUNTER & 637 & 575 & BROAD & 601 & 1051 & METAL & 692 & 714 \\
\hline BLAST & 739 & 642 & LIQUID & 696 & 673 & BUSY & 547 & 567 & NINTH & 675 & 780 \\
\hline BOOST & 774 & 1084 & МАТCH & 589 & 715 & CAFE & 705 & 573 & PHRASE & 870 & 746 \\
\hline CAPE & 635 & 605 & MOTOR & 764 & 575 & CALM & 809 & 628 & PINT & 607 & 715 \\
\hline CELLAR & 681 & 807 & OPEN & 562 & 586 & CHAOS & 1000 & 895 & PLAGUE & 717 & 672 \\
\hline CHARM & 633 & 642 & PINCH & 622 & 649 & CHASM & 1012 & 996 & POLICE & 585 & 622 \\
\hline CHEAP & 802 & 592 & PLATE & 584 & 653 & CHASSIS & 1032 & 1385 & POUR & 609 & 612 \\
\hline CLASSES & 812 & 652 & PRAISE & 673 & 770 & CLICHE & 915 & 1045 & SEW & 695 & 725 \\
\hline CLICK & 725 & 775 & ROOM & 564 & 535 & DOLL & 604 & 541 & SHOE & 556 & 546 \\
\hline CORN & 549 & 535 & SNOB & 633 & 708 & DOLLAR & 658 & 635 & SUGAR & 589 & 575 \\
\hline COUCH & 781 & 865 & SOFT & 613 & 519 & ELITE & 741 & 765 & SUIT & 836 & 782 \\
\hline DEW & 632 & 937 & SOUR & 563 & 503 & FIGHT & 708 & 504 & SWEAT & 623 & 673 \\
\hline DIVINE & 758 & 668 & SUCK & 579 & 624 & FLOOD & 640 & 571 & SWORD & 723 & 770 \\
\hline FAME & 821 & 633 & SUMMIT & 963 & 940 & GNAW & 812 & 925 & THUMB & 616 & 714 \\
\hline FANCY & 662 & 669 & THING & 570 & 745 & GONE & 566 & 618 & TOUCH & 518 & 486 \\
\hline FLOAT & 718 & 688 & TOLL & 618 & 675 & GUESS & 572 & 661 & TOUR & 587 & 534 \\
\hline FOUL & 559 & 544 & TONE & 562 & 553 & HEIR & 941 & 862 & WANT & 672 & 630 \\
\hline FUSE & 877 & 645 & TREAT & 706 & 602 & HONEST & 596 & 644 & WHOM & 875 & 979 \\
\hline GOES & 588 & 516 & WHEEL & 693 & 691 & HONOR & 616 & 676 & WOMAN & 557 & 715 \\
\hline GROW & 599 & 673 & WHIP & 855 & 616 & HOUR & 613 & 615 & WORD & 518 & 569 \\
\hline
\end{tabular}

Note $-N=$ normal reaction time; $D=$ degraded reaction time. 
Appendix D

Word Set B from Experiments 3 and 4 with Reaction Times from Experiment 4

\begin{tabular}{|c|c|c|c|c|c|c|c|c|c|c|c|}
\hline \multicolumn{6}{|c|}{ Regular } & \multicolumn{6}{|c|}{ Exception } \\
\hline Item & $\mathbf{N}$ & $\mathrm{D}$ & Item & $\mathrm{N}$ & $\mathrm{D}$ & Item & $\mathrm{N}$ & D & Item & $\mathbf{N}$ & D \\
\hline ABSENT & 671 & 710 & LEGEND & 752 & 749 & ABOVE & 523 & 664 & LOVE & 477 & 554 \\
\hline ACADEMY & 694 & 1000 & LONE & 575 & 749 & ACRES & 1234 & 799 & MASSAGE & 652 & 1202 \\
\hline AFTERWARD & 947 & 787 & LONELY & 656 & 682 & ALLEGE & 1001 & 1447 & MONDAY & 842 & 826 \\
\hline ALIVE & 549 & 690 & MARKET & 629 & 811 & ANSWERS & 931 & 767 & MORALE & 967 & 942 \\
\hline ASSEMBLY & 632 & 629 & MEMBER & 644 & 775 & BALLET & 847 & 780 & MOVE & 611 & 627 \\
\hline BEAT & 556 & 749 & MINE & 578 & 946 & CELLO & 1002 & 1255 & NONE & 642 & 619 \\
\hline BITE & 578 & 754 & NATION & 921 & 963 & CHAMBER & 659 & 839 & NOTICE & 584 & 868 \\
\hline BOARD & 609 & 891 & NERVE & 655 & 796 & COLONEL & 660 & 991 & OCEAN & 581 & 665 \\
\hline BULLET & 635 & 758 & NOTE & 494 & 537 & COLUMN & 733 & 942 & RAVINE & 1206 & 1352 \\
\hline COLONY & 618 & 714 & PAMPER & 887 & 987 & COPY & 574 & 584 & REGIME & 733 & 1136 \\
\hline CRITIC & 708 & 1166 & PARADE & 711 & 846 & CREATIVE & 687 & 766 & ROUTINE & 675 & 721 \\
\hline CROSS & 668 & 594 & PLASTER & 619 & 759 & DENY & 755 & 700 & SACRED & 915 & 782 \\
\hline DEBATE & 563 & 884 & RANGE & 691 & 702 & DOCTRINE & 637 & 730 & SENATE & 647 & 693 \\
\hline DELAYED & 662 & 708 & SCARED & 736 & 950 & DONE & 542 & 743 & SHOES & 527 & 692 \\
\hline EDIT & 855 & 895 & SHADE & 759 & 682 & FACADE & 719 & 1278 & SOLDIER & 677 & 870 \\
\hline ENTIRE & 570 & 997 & SOURCE & 666 & 628 & FAMINE & 806 & 861 & STOMACH & 682 & 629 \\
\hline EXIST & 624 & 772 & SOUTH & 531 & 534 & FAMOUS & 654 & 976 & SURE & 687 & 753 \\
\hline EXPLICIT & 770 & 1285 & STAND & 513 & 590 & FATHER & 551 & 710 & TONGUE & 631 & 658 \\
\hline FORMER & 576 & 770 & STEM & 590 & 937 & FINDINGS & 977 & 744 & TOUR & 597 & 611 \\
\hline HAVEN & 748 & 1161 & STUDENT & 520 & 583 & GARAGE & 820 & 1256 & VAGUE & 719 & 769 \\
\hline INLAND & 782 & 741 & TEXTILE & 624 & 770 & GLOVE & 641 & 801 & WATCH & 542 & 654 \\
\hline INVITE & 641 & 794 & TROUBLE & 523 & 569 & GROSS & 790 & 844 & WEARING & 827 & 968 \\
\hline INVITED & 833 & 649 & WEST & 506 & 1001 & HEIGHT & 623 & 638 & WEDNESDAY & 1008 & 1163 \\
\hline JUSTIFY & 574 & 642 & WORKSHOP & 571 & 790 & ISLAND & 639 & 732 & WELCOME & 512 & 632 \\
\hline LEATHER & 592 & 777 & ASSIST & 640 & 858 & LAWYER & 582 & 1180 & WORSE & 646 & 1138 \\
\hline
\end{tabular}

Note $-N=$ normal reaction time $D=$ degraded reaction time .

(Received for publication February 7, 1980; revision accepted May 1, 1980.) 